\title{
Heresy and the Church of Q: a reply
}

\author{
Peter A. Tamás · Jarl K. Kampen
}

Published online: 4 May 2014

(C) Springer Science+Business Media Dordrecht 2014

\section{Eppur si muove - Allegedly said by Galileo Galilei}

We are pleased that the editor of this journal was swift in publishing a reply to our review of recent contributions and status of Q-methodology. Steven Brown, Stentor Danielson and Job van Exel have introduced a number of substantive rebuttals whose merits we, predictably, dispute. Rather than succumb to the temptation to engage their argument point by point, we have decided that science is better served by deferring responsibility for critical review to readers who may be interested in using Q-methodology. These articles, and more particularly the references they cite, provide a reasonable starting point for the review necessary before choosing to use Q-methodology.

We found limited evidence of careful review in our own survey of studies that have used Qmethodology. If our detractors are right, and the methodology is fundamentally sound, sloppy application might explain the rather dim view the scientific community seems to take of the methodology. For example, Packer's (2011) well received book on the Science of Qualitative Research devotes no less than five chapters (pages 17-122) to the theme of "The Objective Study of Subjectivity" while not making one mention of Q-methodology or its founders, and a search of the Scopus database of 2010 peer reviewed scientific journals, a database that takes a rather broad view of 'scientific,' turned up only 109 probable hits of which likely only half are Q-methodology studies ${ }^{1}$ We hope that critical review, also recommended by our detractors, will either lead to the justified acknowledgement and flourishing or, alternatively, to the equally justified demise of Q-methodology.

Readers who are by reason of time or competence unable to pick through the details in our exchange and in the referenced material should not use Q-methodology. While there are

${ }^{1}$ Of the 71 articles we were able to retrieve 39 were empirical studies that used Q-methodology.

P. A. Tamás $(\varangle)$ · J. K. Kampen

Research Methodology Group, Wageningen University, Postbus 8130,

6700 EW Wageningen, The Netherlands

e-mail: peter.tamas@wur.nl

J. K. Kampen

e-mail: jarl.kampen@wur.nl 
some circumstances in which ignorance of the inner workings of a method are scientifically acceptable, these require a degree of scientific consensus supported by empirical evidence that is certainly not found in the case of Q-methodology.

On a final note, we are troubled by the reliance of our detractors on evasion, substitution, hyperbole and personalization in their arguments. These tendencies, which were done far better in the Pearson-Yule controversy (see e.g., Agresti 1996, p. 257), are not helpful even in religious debate.

\section{References}

Agresti, A.: An Introduction to Categorical Data Analysis. Wiley, New York (1996)

Brown, S. R., Danielson, S., van Exel, J.: Overly ambitious critics and the Medici Effect: a reply to Kampen and Tamás. Qual. Quant. (2014). doi:10.1007/s11135-014-0007-x

Kampen, J. K., Tamás, P.: Overly ambitious: contributions and current status of Q methodology. Qual. Quant. (2013). doi:10.1007/s11135-013-9944-z

Packer, M.: The Science of Qualitative Research. Cambridge University Press, Cambridge (2011) 